\title{
Palliative care for frail older people
}

\author{
Authors: Laura M Pal ${ }^{A}$ and Lisa Manning ${ }^{B}$
}

\section{Introduction}

It is now widely accepted that palliative care should be available to all those in need regardless of age, diagnosis or care setting. ${ }^{1}$ Despite this, the palliative care needs of older patients are often under assessed and undertreated. ${ }^{2}$ Given that $58 \%$ of patients still die in hospital, ${ }^{1}$ all physicians need to be able to identify and manage the palliative care needs of frail older patients, many of whom will have multiple comorbidities and a significant symptom burden.

\section{Frailty as an indicator for initiating palliative care}

Frailty is a progressive physiological decline in multiple organ systems marked by loss of function, loss of physiological reserve and increased vulnerability to disease and death. ${ }^{3}$ Frail older adults are more susceptible to adverse health outcomes, including delirium, falls, functional decline, reduced mobility, social withdrawal, institutionalisation and death. ${ }^{3,4}$ Frailty is a dynamic process, but transition to a level of worse frailty is more common than improvement. ${ }^{4}$ Frailty is also more common in older adults and in those with multiple comorbidities, but can occur independently of these factors and, therefore, differs from normal ageing. ${ }^{5}$

The prevalence of frailty in the acute hospital setting is difficult to estimate because it depends on the definition used. As expected, the incidence of frailty steadily increases with age. An estimated $4 \%$ of $65-69$-year-old patients meet the criteria for diagnosis, increasing to $26 \%$ of those over 85 years of age. ${ }^{6}$ Given that $63 \%$ of all acute admissions were 65 -years old or more in a recent survey in England, patients with frailty will be an everyday feature of physicians' ward care and more will be referred to outpatient clinics or for investigations. ${ }^{7}$

Frailty has no single widely accepted definition; available definitions are set out in Table 1. One common definition is that frailty is a clinical syndrome in which three or more of unintentional weight loss, self-reported fatigue, slow walking, muscular weakness and low levels of energy are present. If one or two are present, the patient is defined as pre-frail. ${ }^{4}$ Alternatively, the concept of frailty has been described as a consequence of an accumulation of deficits over time. Deficits include disabilities, diseases, cognitive impairment,

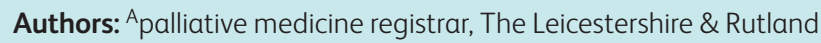
Hospice, Leicester, UK; ${ }^{B}$ Clinical research fellow (stroke), Leicester Royal Infirmary, Leicester, UK psychosocial risk factors and geriatric syndromes (ie falls, delirium and urinary incontinence). ${ }^{8,9}$ The number of deficits can be used to calculate an individual's frailty index, which is strongly correlated with risk of death. ${ }^{10}$

Numerous ways to measure frailty have been described. The Clinical Frailty Scale is a seven-point scale, ranging from 1 (very fit) to 7 (severely frail) (Box 1). ${ }^{11}$ It can assist in prognostication, with higher scores being associated with increasing risk of institutionalisation and death. Even mild frailty is associated with a $50 \% 5$-year mortality. ${ }^{9}$

The end-of-life trajectory of the frail is well documented, with slowly progressive functional decline in the years preceding death with only a slight acceleration in this decline as death approaches. Thus, identifying the start of a 'terminal phase' is challenging. ${ }^{12}$ This, coupled with the complex needs and high symptom burden of this group, makes it appropriate to introduce palliative care from diagnosis, with a naturally increasing emphasis on this approach as frailty advances. ${ }^{10}$

\section{Cornerstones of palliative management}

Managing the needs of frail older people requires a thorough and holistic assessment. Mortality rates for frail older people in the year following discharge from acute medical units (AMUs) are high (26\% in one series). ${ }^{13}$ Therefore, acute hospital admissions present an ideal opportunity to identify frail adults, start anticipatory care planning and begin discussions with patients and their families about their preferences for future care and dying. Identification of such patients for the general practitioner's (GP's) palliative care register will improve outcomes for patients.

\section{Assessment}

Assessment of the frail should aim to do the following:

1 identify and treat reversible causes of decline

2 detect and control troublesome symptoms, and form individualised treatment plans

3 screen for weight loss, pain, dyspnoea falls, depression and insomnia

4 assess severity of frailty and identify those with worse prognostic indicators

5 communicate to the patient and the family the prognostic implications of frailty, its likely course, and available support.

Comprehensive geriatric assessment (CGA) enables the admitting team to move away from assessing single-system 
Table 1. Common definitions of frailty.

\begin{tabular}{|c|c|c|c|c|}
\hline Definition & Components & Grades and/or scoring & Measurement & References \\
\hline Phenotype based & Performance on five variables & Robust, pre-frail or frail & Performance based & Fried et $a l^{4}$ \\
\hline Frailty Index & Number of deficits accumulated & $0-1$ & Comprehensive geriatric assessment & Mitnitski et $a l^{8}$ \\
\hline $\begin{array}{l}\text { Clinical Frailty } \\
\text { Scale }\end{array}$ & $\begin{array}{l}\text { Single descriptor of a person's } \\
\text { state of frailty }\end{array}$ & $\begin{array}{l}\text { Seven-point scale, from } \\
\text { very fit to severely frail }\end{array}$ & Clinical judgement & Rockwood et al ${ }^{11}$ \\
\hline
\end{tabular}

illnesses and carry out a more holistic assessment of need, which lends itself to a palliative care approach from the outset. The major components of the assessment are outlined in Table 2. ${ }^{14}$

In acute hospitals, frail older patients that receive inpatient CGA on specialist older person care wards are more likely to return home, less likely to have cognitive or functional decline, and have lower in-hospital mortality rates than do those who are admitted to other ward settings. ${ }^{15}$ Indeed, the recent toolkit from the Royal College of Physicians (Acute medical care for frail older people) recommends that, in any admitted patient, the presence of one or more frailty syndromes (Box 2) should prompt consideration of the need for a fuller holistic assessment, and for the consequent management plan to be integrated across community and hospital services. ${ }^{13}$

\section{Anticipatory and advance care planning}

The principle aim of advance care planning (ACP) is to establish the goals of care for an individual based on a holistic assessment, appropriate clinical treatment and their personal values. ACP in older people makes it more likely that patient's wishes are known and achieved, improves end-of-life care and patient and family satisfaction, and reduces stress, anxiety and depression in surviving relatives. ${ }^{16}$

Some patients might wish to make formal written advance statements of their wishes, an advance decision to refuse treatment (ADRT) or appoint a lasting power of attorney to ensure that their wishes are respected if capacity is lost. For others, they might only express their preferences in discussion with professionals who will need to share the written record. It is important to start this process early because the patient might need time to take on board the information about their clinical situation and prognosis, and to feel able to discuss their wishes for the future. It is also important to undertake this while a patient has capacity. In those who already lack capacity, the focus when making anticipatory care plans should be to take into account previous expressed wishes and ensure good communication with relatives to be able to act in the patient's best interests.

Importantly, curative approaches, such as treatment of infections, or invasive investigations, can be included in an ACP. However, such interventions are likely to become clinically less beneficial, and potentially more harmful, as frailty progresses, with symptom control becoming an increasing focus towards the end of life.

\section{Symptom control}

\section{Pain and other symptoms}

In the last year of life, symptoms including pain, anorexia, low mood, confusion, constipation, insomnia and incontinence
Box 1. The Canadian Society of Health and Aging (CSHA) Clinical Frailty Scale. ${ }^{11}$

1 Very fit: robust, active, energetic, well motivated and fit; these people commonly exercise regularly and are in the most fit group for their age

2 Well: without active disease, but less fit than people in category 1

3 Well, with treated comorbid disease: disease symptoms are well controlled compared with those in category 4

4 Apparently vulnerable: although not frankly dependent, these people commonly complain of being 'slowed up' or have disease symptoms

5 Mildly frail: with limited dependence on others for instrumental activities of daily living

6 Moderately frail: help is needed with both instrumental and non-instrumental activities of daily living

7 Severely frail: either completely dependent on others for the activities of daily living or terminally il

\section{Box 2. Frailty syndromes.}
$>$ Falls
Delirium and dementia
$>$ Polypharmacy
$>$ Incontinence
$>$ Immobility
End-of-life care

are common, as well as symptoms caused by any underlying comorbidities. ${ }^{17}$ Achieving good symptom control is associated with higher functional status, better quality of life, and greater patient and relative satisfaction.

Pain is widely underassessed and undertreated in older patients, especially those with cognitive impairment. ${ }^{2}$ This is particularly worrying given that a recent study showed an independent association between self-reported pain and frailty in older patients, proposing that persistent pain directly worsens frailty. ${ }^{18}$

When treating pain and other symptoms in the frail, as well as symptoms in the terminal phase, the same classes of drug should be used as in younger patients. However, many of the commonly used drugs used to achieve symptom control, such as opioids and benzodiazepines, are associated with higher rates of adverse 


\section{Key points}

Frailty is a clinical syndrome associated with increased risk of functional disability, dependency, institutionalisation and death

Frailty is a dynamic process, but transition to a level of worse frailty is more common than improvement

The palliative care needs of older people are often under assessed and undertreated

Comprehensive specialist assessment during acute admissions reduces the risk of cognitive or functional decline, and death

Palliative care in the form of anticipatory care planning, consideration of addition to the general practitioner's palliative care register and symptom control should be initiated early, and can include curative treatments, which might improve functioning, and quality of life

KEY WORDS: Palliative care, frail, older patients, frailty

events in the frail, ${ }^{10}$ often causing a reluctance to prescribe them appropriately. To counter this, patients should be started at low doses and be titrated upwards slowly to optimal doses. Regular review is important not only to recognise adverse effects, but also to ensure that drugs reach therapeutic levels.

\section{Managing polypharmacy}

In an older population, multiple comorbidities leading to polypharmacy and adverse drug events contribute significantly to poorer health, hospital admissions, morbidity, mortality and length of hospital stay. ${ }^{19} \mathrm{~A}$ sensible approach in managing polypharmacy in the frail is to continue drugs that contribute to symptom control while stopping those causing adverse effects, or preventative drugs that are unlikely to provide benefit in those with short life expectancies (eg statins or third-line drugs for hypertension). Specific tools are available to assist in this process (eg STOPP/START). ${ }^{20}$ This approach also enables new symptom-controlling medications to be started with less concern over drug interactions and increasing tablet burden.

\section{When is specialist palliative care necessary?}

Geriatric and palliative medicine have much in common. Both aim to provide complete assessment of a patient's medical, psychological and social needs to optimise care and quality of life. In addition, both aim to treat patients as individuals, incorporate family into care and utilise a multidisciplinary team to obtain best outcomes. Therefore, it can be difficult to decide when to involve specialist palliative care teams in the care of frail older patients.

Given the complex nature of those with frailty, clinicians with specialist geriatric knowledge should lead the management of the frail, particularly early during the disease process, when
Table 2. Key components of Comprehensive Geriatric Assessment. ${ }^{14}$

\begin{tabular}{|c|c|}
\hline Domain & Assessment \\
\hline Medical & $\begin{array}{l}\text { Review of acute and chronic conditions } \\
\text { Medication review } \\
\text { Assessment of nutritional status } \\
\text { Problem list }\end{array}$ \\
\hline Psychological & $\begin{array}{l}\text { Cognitive assessment } \\
\text { Identify anxiety and/or depression }\end{array}$ \\
\hline $\begin{array}{l}\text { Functional } \\
\text { capacity }\end{array}$ & $\begin{array}{l}\text { Ability to perform activities of daily living } \\
\text { Gait and balance assessment } \\
\text { Ability to exercise }\end{array}$ \\
\hline $\begin{array}{l}\text { Social } \\
\text { circumstances }\end{array}$ & $\begin{array}{l}\text { Formal and/or informal support available } \\
\text { Financial situation } \\
\text { Entitlement to social and financial support }\end{array}$ \\
\hline $\begin{array}{l}\text { Home } \\
\text { environment }\end{array}$ & $\begin{array}{l}\text { Home facilities and/or equipment } \\
\text { Use and/or potential use of assisted } \\
\text { technology } \\
\text { Access to local resources and support }\end{array}$ \\
\hline
\end{tabular}

improving frailty and halting progression might be possible. A pragmatic approach would be to refer patients with persistent or refractory symptoms for a palliative care opinion. Thereafter, care might be shared, lead by the GP only or occasionally given ongoing support by specialist palliative care services. Referral should be made based on problems rather than prognosis to ensure timely referrals that are most likely to benefit patients.

\section{Conclusions}

Frailty is associated with adverse health outcomes and, therefore, has important implications for the care needs of older adults. It is important that clinicians can recognise and objectively measure frailty to engage patients and their families in discussions and decisions about treatment plans and prognosis.

\section{References}

1 Department of Health. End of Life Care Strategy: promoting high quality care for adults at the end of their life. London: DOH, 2008.

2 Davies E, Higginson IJ. Better palliative care for older people. Copenhagen: WHO, 2004.

3 Moorhouse P, Rockwood K. Frailty and its quantitative clinical evaluation. J R Coll Physicians Edinb 2012;42:333-40.

4 Fried LP, Tangen CM, Walston J et al. Frailty in older adults: evidence for a phenotype. J Gerontol A Biol Sci Med Sci 2001;56:M146-56.

5 Fulop T, Larbi A, Witkowski et al. Aging, frailty and age-related diseases. Biogerontology 2010;11:547-63.

6 Song X, Mitnitski A, Rockwood K. Prevalence and 10-year outcomes of frailty in older adults in relation to deficit accumulation. $J \mathrm{Am}$ Geriatr Soc 2010;58:681-87.

7 Health and Social Care Information Centre. Hospital episode statistics. Leeds: HSCIC, 2013.

8 Mitnitski AB, Mogilner AJ, Rockwood K. Accumulation of deficits as a proxy measure of aging. ScientificWorldJournal 2001;1:323-36. 
9 Rockwood K, Fox RA, Stolee P et al. Frailty in elderly people: an evolving concept. CMAJ 1994;150:489-95.

10 Koller K, Rockwood K. Frailty in older adults: implications for endof-life care. Cleve Clin J Med 2013;80:168-74.

11 Rockwood K, Song X, MacKnight C et al. A global clinical measure of fitness and frailty in elderly people. CMAJ 2005;173:489-95.

12 Covinsky KE, Eng C, Lui L-Y et al. The last 2 years of life: functional trajectories of frail older people. J Am Geriatr Soc 2003;51:492-8.

13 Royal College of Physicians. Acute care toolkit 3: Acute medical care for frail older people. March 2012. London: RCP, 2012. www.rcplondon.ac.uk/sites/default/files/acute-care-toolkit-3.pdf [Accessed 28 March 2014].

14 British Geriatrics Society. Comprehensive assessment of the frail older patient. Good practice guide. London: BGS, 2010.

15 Ellis G, Whitehead MA, Robinson D et al. Comprehensive geriatric assessment for older adults admitted to hospital: meta-analysis of randomised controlled trials. BMJ 2011;343:d6553.

16 Detering KM, Hancock AD, Reade MC, Silvester W. The impact of advance care planning on end of life care in elderly patients: randomized controlled trial. BMJ 2010;340:c1345.
17 Addington-Hall J, Altmann D, McCarthy M. Variations by age in symptoms and dependency levels experienced by people in the last year of life, as reported by surviving family, friends and officials. Age Ageing 1998;27:129-36.

18 Shega JW, Dale W, Andrew M et al. Persistent pain and frailty: a case for homeostenosis. J Am Geriatr Soc 2012;60:113-7.

19 Mannesse CK, Derkx FH, de Ridder MA et al. Contribution of adverse drug reactions to hospital admission of older patients. Age Ageing 2000;29:35-9.

20 Gallagher P, Baeyens J-P, Topinkova E et al. Inter-rater reliability of STOPP (Screening Tool of Older Persons' Prescriptions) and START (Screening Tool to Alert doctors to Right Treatment) criteria amongst physicians in six European countries. Age Ageing 2009;38:603-6.

Address for correspondence: Dr LM Pal, The Leicestershire \& Rutland Hospice, Groby Road, Leicester LE3 9QE.

Email: laurarowlands@doctors.org.uk

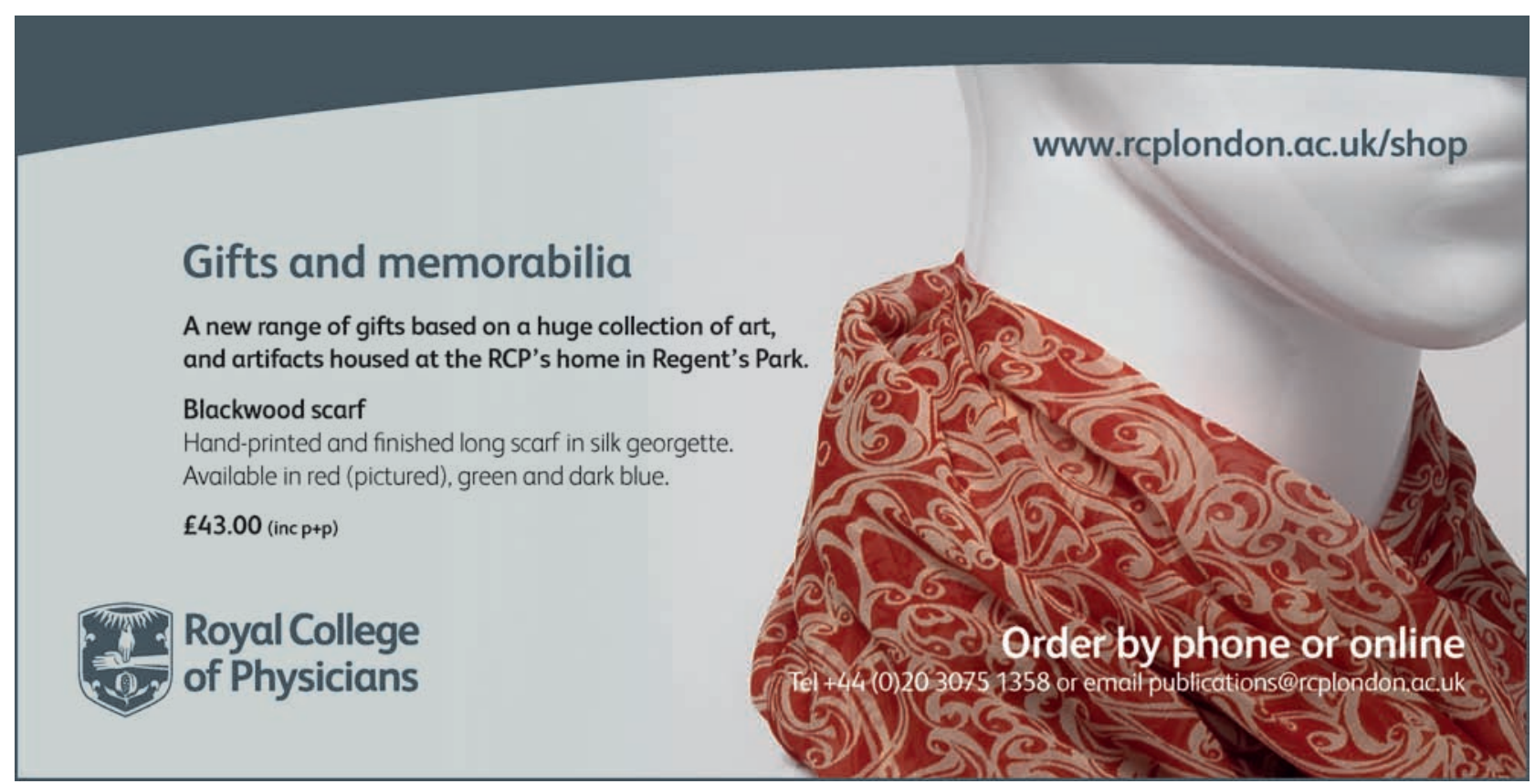

